\title{
RADIATION HARDNESS OF MOS STRUCTURES EXPOSED TO HIGH-ENERGY IONS
}

\begin{abstract}
MOS structures exposed to $305 \mathrm{MeV} \mathrm{Kr}$ and $710 \mathrm{MeV}$ Bi ions irradiation with fluences of $10^{9} \mathrm{~cm}^{-2}$ and $10^{10} \mathrm{~cm}^{-2}$ were investigated by capacitance measuring methods ( $C-V, C-t)$, completed by quasistatic low-frequency $C-V$ and DLTS measurements.

The irradiated MOS structures were functional in spite of a high density of radiation defects. The electric activity of the defects brought a sharp decrease in the generation parameters $t_{r}$ and $\tau_{g}$. The parameters of six deep levels were detected in the MOS structures exposed to 710 $\mathrm{MeV} \mathrm{Bi} \mathrm{ions} \mathrm{irradiation.} \mathrm{Five} \mathrm{of} \mathrm{these} \mathrm{levels} \mathrm{with} \mathrm{energies} 0.52 \mathrm{eV}, 0.14 \mathrm{eV}, 0.17 \mathrm{eV}, 0.25 \mathrm{eV}, 0.27 \mathrm{eV}$ were radiation defects.

Keywords: Silicon; high-energy ion implantation; irradiation; MOS structure; capacitance method; DLTS
\end{abstract}

\section{Introduction}

Recently there has been a growing interest in the use of highenergy heavy ion irradiation for electronic materials modification [1]. The issues involved in high-energy ion implantation are open both on the fundamental [2] as well as on the applied aspects of the process [3]: the understanding of defect creation and its kinetics on the one hand, and the application of deep implantation on the other hand.

This study is also very useful for knowledge of the radiation hardness of electronic devices in a high radiation environment in a reactor laboratory or in the outer space.

The scope of this paper is to investigate the effect of the 305 $\mathrm{MeV} \mathrm{Kr}$ and $710 \mathrm{MeV}$ Bi ion irradiation on the electrical properties of MOS structures.

We used the capacitance-voltage $C$ - $V$ method to determine the flat-band voltage $U_{F B}$ and the free carriers concentration profile $n(x)$ in the structures before and after irradiation. The kinetics of the generation process that takes place in the space charge region was diagnosed by the non-equilibrium $C-t$ method [4]. Parameters obtained from this method, the relaxation time $t_{r}$, the generation lifetime of minority charge carriers $\tau_{g}$ and the surface generation velocity $S_{g}$ characterize the electrical behaviour of defects in the MOS structure.

The energy distribution of the insulator-semiconductor interface trap density $D_{i t}$ was obtained from the low frequency $C-V$ curve. We used the quasistatic charge-voltage method [5].

In particular, deep level transient spectroscopy (DLTS) [6] proved to be highly applicable because of its good sensitivity, and specific defect centers with well-defined signatures can be moni- tored to concentrations of $\sim 10^{-5}$ below the dopant concentration. We used the standard capacitance DLTS method with electrical excitation.

\section{Experiment}

An $n$-type Czochralski-grown antimony doped (100)-oriented homogeneous wafer of silicon with resistivity $2-5 \Omega \mathrm{cm}$ and thickness $300 \mu \mathrm{m}$ was used as a substrate of the MOS structure. The gate $\mathrm{SiO}_{2}$ layers were prepared by thermal oxidation in the atmosphere of dry oxygen at $1050{ }^{\circ} \mathrm{C}$ for 90 minutes. The thickness of the $\mathrm{SiO}_{2}$ layer was about $100 \mathrm{~nm}$. All gates were vapour deposited and patterned photolithographically. After manufacturing the MOS structures, the sample was annealed in $\mathrm{N}_{2}+\mathrm{H}_{2}$ at $460{ }^{\circ} \mathrm{C}$ for 20 minutes. The ohmic contact from the backside of the wafer was prepared by vapour deposition of $\mathrm{Al}$.

Afterwards, the MOS structures were exposed to $305 \mathrm{MeV} \mathrm{Kr}$ ion irradiation with a fluence of $10^{9} \mathrm{~cm}^{-2}$ (samples D1) and a fluence of $10^{10} \mathrm{~cm}^{-2}$ (samples D2) and to $710 \mathrm{MeV}$ Bi ion irradiation with a fluence of $10^{9} \mathrm{~cm}^{-2}$ (samples D8) and with a fluence of $10^{10} \mathrm{~cm}^{-2}$ (samples D6) at the Joint Institute for Nuclear Research in Dubna, Russia [7].

The non-irradiated MOS structure (D0) and the irradiated MOS structures (D1, D2, D6, D8) were characterized by $C-V$, low-frequency $C-V$ and $C-t$ methods. High frequency capacitancevoltage $C-V$ and non-equilibrium capacitance-time $C-t$ measurements were performed using the $42801 \mathrm{MHz} C$ Meter/C-VPlotter Hewlett-Packard [8]. Quasistatic low frequency $C-V$ measurements were performed using the Keithley 595 Quasistatic CV Meter. The MOS structures (D0) and irradiated (D6, D8) were also investigated by a standard DLTS method. This method is a high-frequency transient capacitance thermal scanning method, where the capac-

\footnotetext{
* L. Harmatha, L. Stuchlíková, P. Písečný

Department of Microelectronics, Faculty of Electrical Engineering and Information Technology, Slovak University of Technology, Ilkovičova 3 , 81219 Bratislava, Slovakia, fax: ++421-2-654 23480, E-mail:ladislav.harmatha@stuba.sk
} 
itance transient effect in the potential barrier of a semiconductor is caused by an electrical excitation pulse. DLTS measurements were performed using a BioRad boxcar detection system.

\section{Results and Discussion}

The MOS structures (sample D0) used in this experiment were of high quality, having a low density of defects. This presumption was verified by many measured DLTS spectra under different measuring conditions (Fig. 1).

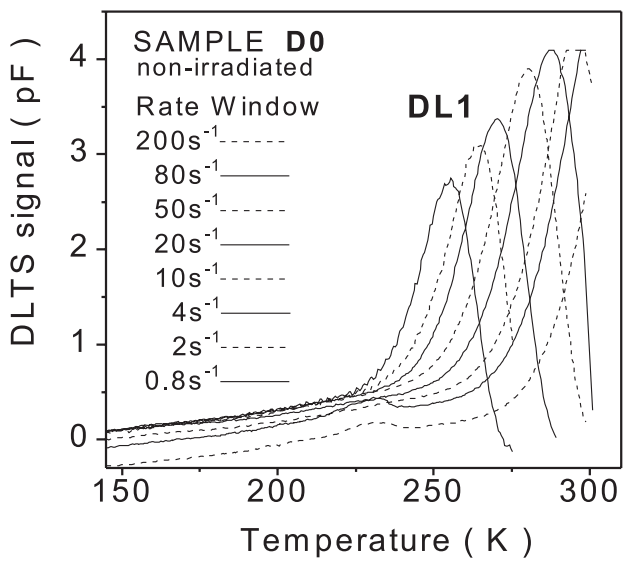

Fig. 1. Typical measured DLTS spectra of the sample D0 at optimal measuring conditions $\left(U_{R}=-1 \mathrm{~V}, U_{F}=-0.25 \mathrm{~V}, t_{F}=0.8 \mathrm{~ms}\right)$.

$D L 1$ is the determined energy deep level.

We found only one deep level DL1 $(0.61 \mathrm{eV})$ with a very low concentration of $2 \times 10^{13} \mathrm{~cm}^{-3}$. This deep level corresponds to the presence of $\mathrm{Au}(0.59 \mathrm{eV})[9]$.

In $C-V$ measured curves (Fig. 2), we observed a rise in the positive defect charge in the oxide and at the interface with the silicon substrate, which resulted in an increased flat band voltage (Tab. 1).

The antimony doped MOS structures had the same or only slightly lower concentration of impurities, $N_{D}$, after irradiation with

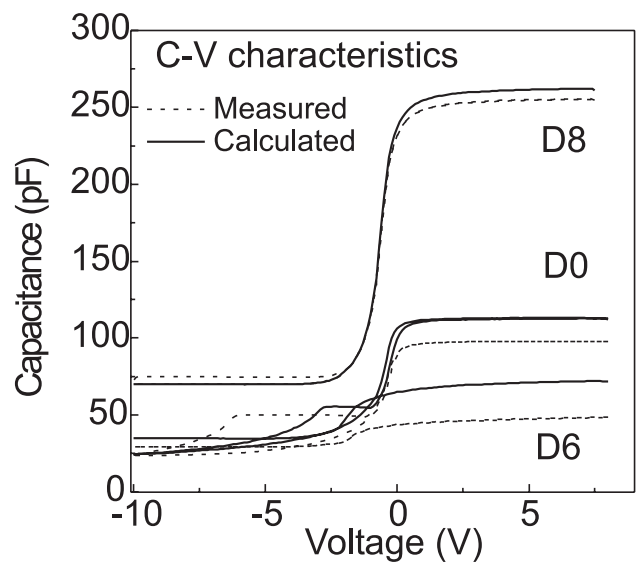

Fig. 2. MOS structures D0, D6, D8 measured and calculated $C-V$ curves; the calculated $C-V$ curves include a correction for the effect of conductance upon the measurement of the capacitance.

$\mathrm{Kr}$ and $\mathrm{Bi}$ ions. Significant changes in the parameters of the MOS structure were observed in the non-equilibrium state. In $C-t$ measurements we observed a marked decrease of the relaxation time, tr, see Fig. 3.

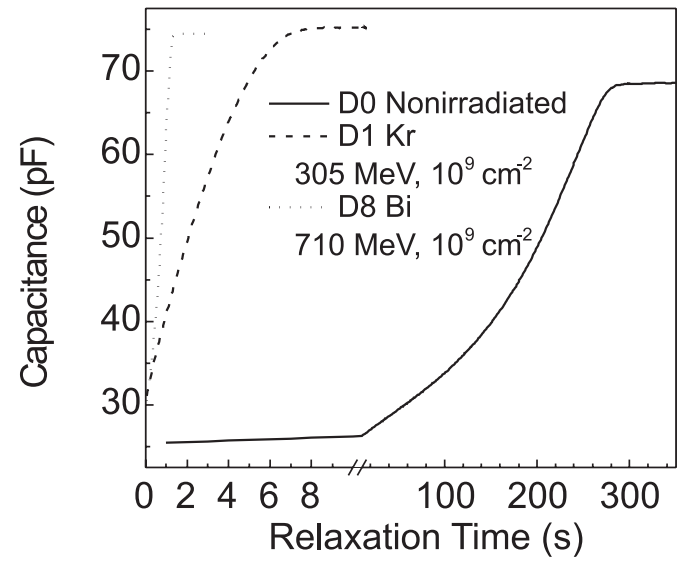

Fig. 3. MOS structures D0, D1, D8 measured C-t curves of MOS structure before and after irradiation by $\mathrm{Kr}$ and Bi ions with the same fluence $10^{9} \mathrm{~cm}^{-2}$

Parameters extracted from $C-V$, low-frequency $C-V$ and $C-t$ measurements on MOS structures. The values of $D_{i t}$ were determined for the level $0.22 \mathrm{eV}$ above the midgap (Fig. 6).

\begin{tabular}{|c|c|c|c|c|c|c|}
\hline Sample & $\begin{array}{l}U_{F B} \\
(\mathrm{~V})\end{array}$ & $\begin{array}{c}N_{D} \\
\left(\mathrm{~m}^{-3}\right)\end{array}$ & $\begin{array}{c}t_{r} \\
(\mathrm{~s})\end{array}$ & $\begin{array}{c}\tau_{g} \\
(\mu \mathrm{s})\end{array}$ & $\begin{array}{c}S_{g} \\
\left(\mathrm{~ms}^{-1}\right)\end{array}$ & $\begin{array}{c}D_{i t} \\
\left(\mathrm{~m}^{-2} \mathrm{eV}^{-1}\right)\end{array}$ \\
\hline D0 - nonirradiated & -0.1 & $1.22 \times 10^{21}$ & 487 & 472 & $2.2 \times 10^{-3}$ & $9.1 \times 10^{14}$ \\
\hline $\mathrm{D} 1-\mathrm{Kr}, 305 \mathrm{MeV}, 10^{9} \mathrm{~cm}^{-2}$ & -0.4 & $1.1 \times 10^{21}$ & 10 & 3.9 & $3.1 \times 10^{-3}$ & $2.4 \times 10^{15}$ \\
\hline $\mathrm{D} 2-\mathrm{Kr}, 305 \mathrm{MeV}, 10^{10} \mathrm{~cm}^{-2}$ & -1.2 & $0.98 \times 10^{21}$ & 1.9 & 0.8 & $1.3 \times 10^{-1}$ & $1.3 \times 10^{16}$ \\
\hline $\mathrm{D} 8-\mathrm{Bi}, 710 \mathrm{MeV}, 10^{9} \mathrm{~cm}^{-2}$ & -0.5 & $1.1 \times 10^{21}$ & 1.7 & 1.3 & $4.5 \times 10^{-1}$ & $1.86 \times 10^{16}$ \\
\hline D6 - Bi, $710 \mathrm{MeV}, 10^{10} \mathrm{~cm}^{-2}$ & no $C-V$ & - & no $C-t$ & - & - & no lf $C-V$ \\
\hline
\end{tabular}


The rise in the density of radiation defects is expressed quantitatively through parameters $\tau_{g}$ and $S_{g}$ (Tab. 1). The highest density of electrically active defects was found in the case of Bi ions with higher energies than those of $\mathrm{Kr}$. Remarkable differences in the generation parameters were observed also in dependence on the fluence of irradiation. In Fig. 4 one can see the shortening of the time of relaxation after irradiation by $\mathrm{Kr}$ ions with a higher fluence.

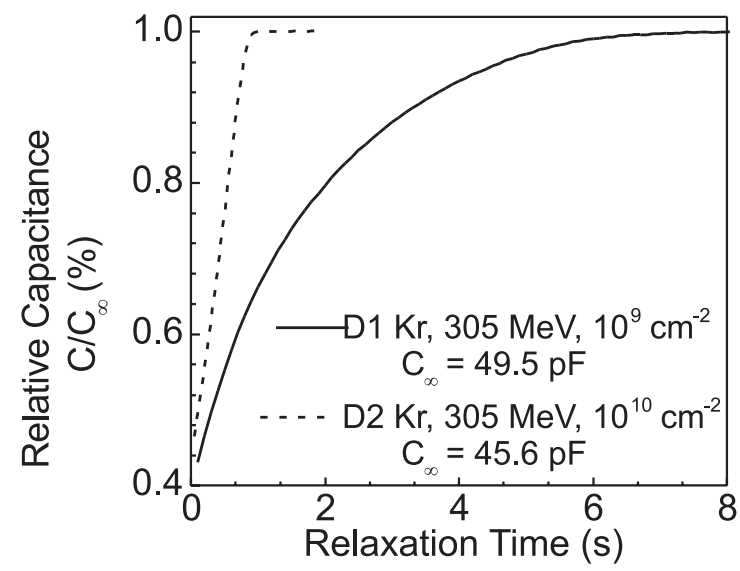

Fig. 4. MOS structures D1 and D2 measured C-t curves of MOS structure after Kr ion irradiation with fluences $10^{9} \mathrm{~cm}^{-2}$ and $10^{10} \mathrm{~cm}^{-2}$

In the case of irradiating with ions of Bi with a fluence of $10^{10} \mathrm{~cm}^{-2}$ a significant increase in the conductivity of the insulating layer was observed (Fig. 5).

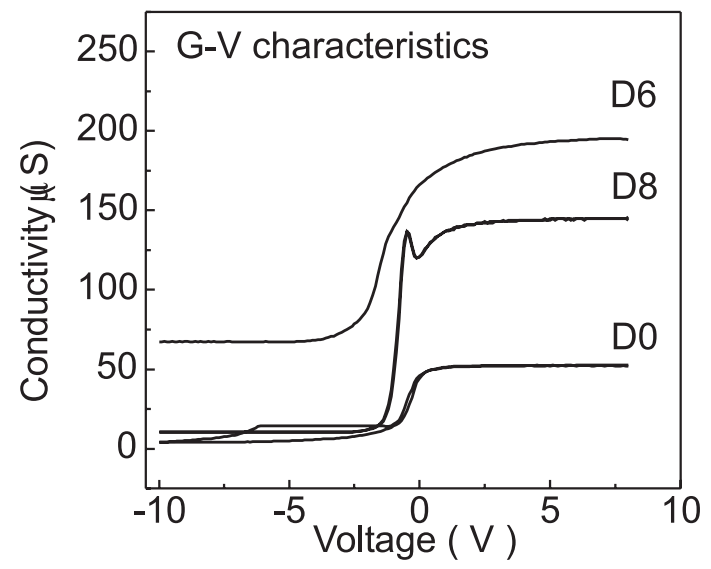

Fig. 5. MOS structures D0, D6, D8 measured G-V curves - conductivity from applied voltage.

$C-V$ measurements and the calculation of $D_{i t}$ (Fig. 6) reveal that the growing dose and energy of implanted ions increase the density, $D_{i t}$. A similar trend can be observed also in the change of the surface generation velocity, $S_{g}$. One can deduce that the quality of the $\mathrm{Si}-\mathrm{SiO}_{2}$ deteriorates. In spite of that the irradiated MOS structures still remain their capacitance properties and functionality.

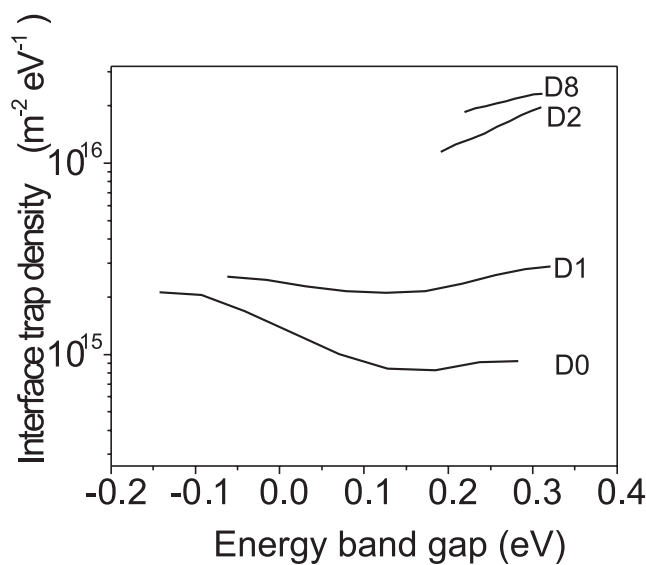

Fig. 6. The energy distribution of the $\mathrm{Si}_{-} \mathrm{SiO}_{2}$ interface trap density. D0 - nonirradiated, D1 - Kr, $305 \mathrm{MeV}, 10^{9} \mathrm{~cm}^{-2}, \mathbf{D} 2-\mathrm{Kr}, 305 \mathrm{MeV}$, $10^{10} \mathrm{~cm}^{-2}$ and $\mathbf{D} 8-\mathrm{Bi}, 710 \mathrm{MeV}, 10^{9} \mathrm{~cm}^{-2}$.

The measured DLTS spectra of the MOS structures after Bi ion irradiation with fluences $10^{9} \mathrm{~cm}^{-2}$ and $10^{10} \mathrm{~cm}^{-2}$ (D6 and D8) exhibit a strong deviation from an exponential dependence (Fig. 7).

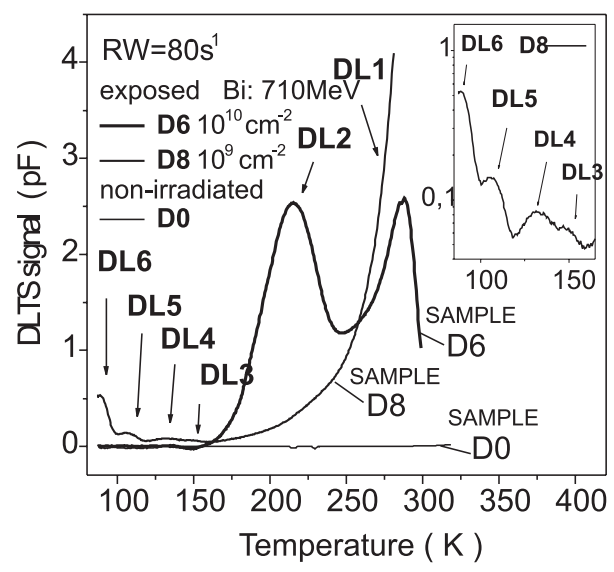

Fig. 7. Typical measured DLTS spectra of the samples D0, D6, D8 for rate window $80 \mathrm{~s}^{-1}$ at the same measuring conditions (reverse voltage $U_{R}=-3 \mathrm{~V}$, filling pulse $U_{F}=-1.1 \mathrm{~V}$, and pulse time $t_{F}=0.8 \mathrm{~ms}$ ).

DL1-DL6 are the determined energy deep levels.

This can be caused by the presence of several mutually influencing deep energy levels. Six peaks labelled DL1, DL2, DL3, DL4, DL5 and DL6 were detected. These deep levels DL1-DL6 are traps of majority charge carriers (electrons). The values of the activation enthalpies (En of electron deep levels and the capture 


\begin{tabular}{|c|c|c|c|c|c|c|c|}
\hline \multirow[t]{2}{*}{ Deep Levels } & \multirow{2}{*}{$\begin{array}{c}\text { activation } \\
\text { enthalpies } \\
\Delta E_{n}(\mathrm{eV})\end{array}$} & \multirow{2}{*}{$\begin{array}{c}\text { cross } \\
\text { section } \\
\sigma_{n}\left(\mathrm{~cm}^{-2}\right)\end{array}$} & \multicolumn{3}{|c|}{ concentration $\left(\mathrm{cm}^{-3}\right)$} & \multirow{2}{*}{$\begin{array}{l}\text { Temperature at } \\
\mathrm{RW}=100 \mathrm{~s}^{-1}\end{array}$} & \multirow{2}{*}{$\begin{array}{l}\text { Similar traps } \\
\text { in literature }\end{array}$} \\
\hline & & & sample D0 & sample D6 & sample D8 & & \\
\hline DL1 & 0.611 & $1.8 \times 10^{-15}$ & $2 \times 10^{13}$ & $3 \times 10^{15}$ & $1 \times 10^{15}$ & 305.4 & $\mathrm{Au}, 0.59 \mathrm{eV}[8]$ \\
\hline DL2 & 0.523 & $1.9 \times 10^{-13}$ & no detect & $1 \times 10^{15}$ & $4 \times 10^{14}$ & 223.0 & E - centre [8] \\
\hline DL3 & 0.269 & $2.9 \times 10^{-16}$ & no detect & no detect & $7 \times 10^{13}$ & 152.1 & $\mathrm{~V}^{-2}[9]$ \\
\hline DL4 & 0.246 & $1.2 \times 10^{-16}$ & no detect & no detect & $9 \times 10^{13}$ & 134.2 & $\mathrm{~V}^{-2}[9]$ \\
\hline DL5 & 0.171 & $1.3 \times 10^{-15}$ & no detect & no detect & $2 \times 10^{14}$ & 107.8 & A - centre [8] \\
\hline DL6 & 0.143 & $4.9 \times 10^{-16}$ & no detect & no detect & $7 \times 10^{14}$ & 88.1 & A - centre [8] \\
\hline
\end{tabular}

cross section for electrons $\sigma_{n}$ were determined from the Arrhenius diagram using the known equations [6] (they are listed in Tab. 2).

In principle it was shown, see Fig. 7, that the deep energy deep DL1 was found in all the three investigated samples D0, D6, D8, while the deep energy level DL2 can be detected only in the structures irradiated by $\mathrm{Bi}$ ions. We can suppose that it was a radiation defect with an activation enthalpy of $0.52 \mathrm{eV}$, which probably corresponds to an $\mathrm{E}$ - centre (vacancy- phosphorous) in irradiated $\mathrm{Si}$ [9]. This deep level dominates in structure D6.

DL3, DL4, DL5 and DL6 peaks were detected only in D8 structures irradiated by Bi ions with fluency $10^{9} \mathrm{~cm}^{-2}$. These are radiation defects. We suppose that DL3 $(0.27 \mathrm{eV})$ and DL4 (0.25 $\mathrm{eV})$ deep level are divacancies $\mathrm{V}^{-2}$ in $\mathrm{Si}$ [10] created by the implantation process and DL5 $(0.17 \mathrm{eV})$ and DL6 $(0.14 \mathrm{eV})$ correspond probably to the A - centre (vacancy-oxygen) in irradiated $\mathrm{Si}$ [11].

\section{Conclusion}

From the capacitance $C-V$ and $C-t$ measurements we found that MOS structures irradiated by high energies and doses of $\mathrm{Kr}$ and $\mathrm{Bi}$ ions were functional in spite of a high density of radiation defects. In the case of $\mathrm{Bi}$ ions with a higher energy than that of $\mathrm{Kr}$ ions, the conductivity of the insulating layer increased. We did not observe a decrease in the concentration of shallow impurities in irradiated MOS structures. The radiation defects created at the $\mathrm{Si}$ $\mathrm{SiO}_{2}$ interface increased the trap density and their electrical activity.

We detected six deep levels in MOS structures irradiated by Bi ions with energy $710 \mathrm{MeV}$ and fluency $10^{9}$ and $10^{10} \mathrm{~cm}^{-2}$. Five of them, DL2-DL6, were produced by radiation. DL3-DL6 levels cannot be detected under higher fluency $\left(10^{10} \mathrm{~cm}^{-2}\right)$. Our interpretation of this fact is following: irradiation with a fluency of $10^{10} \mathrm{~cm}^{-2}$ caused gettering of DL3-DL6 defects. This fluency also causes great oxide layer damage. At the same time, the concentration of DL2 defect in structure D6 rose strongly.

\section{Acknowledgements}

This work was supported by the grant of the Slovak Grant Agency Vega, Project 1/3091/06.

\section{References}

[1] SCRIVASTAVA, P.C., PANDEY, S. P., SINHA, O. P., AVASTI, D. K., ASOKAN, K.: Nuclear Inst. and Methods in Physics Research $B, 1999$, vol. 156, pp. 105-109.

[2] NEUSTROEV, E. P., ANTONOVA, I. V., POPOV, V. P., STAS, V. F., SKURATOV, V. A., DIDYK, A. YU.: Nuclear Instr. and Methods in Physics Research B, 2000, vol. 171, pp. 443-447.

[3] YARYKIN, N., CHO, C. R., ZUHR, R., ROZGONYI, G.: Physica B, 1999, vol. 273-274 pp. 485-488.

[4] ZERBST, M.: Z. Angew. Physics, 1966, vol. 22, pp. 30-36.

[5] PÍSEČNÝ, P., ṪAPAJNA, M., HARMATHA, L., VRBICKÝ, A.: Journal of Electrical Engineering, 2004, vol. 55, pp. 95-99.

[6] LANG, D. V.: J. Appl. Phys., 1974, vol. 45, pp. 3014-3023.

[7] NEUSTROEV, E. P., ANTONOVA, I. V., OBODNIKOV, V. I. POPOV, V. P., SKURATOV, V. A., SMAGULOVA, S. A., DIDYK, A.YU.: Nuclear Instr. and Methods in Physics Research B, 1998, vol. 146, pp. 323-328.

[8] GURNIK, P., HARMATHA, L.: J. Electrical Engineering, 1997, vol. 48. pp. 52-56.

[9] FUKUOKA, N., YONEYAMA, M., HONDA, M., ATOBE, K.: Jpn. J. Appl. Phys., 1993, vol. 32, pp. 2059-2062.

[10] WATKINS, G. D.: The lattice vacancy in silicon. In: Deep Centers in Semiconductors (Si). Edited by S. T. Pantelides, Gordon and Breach Science Publishers, 1986, pp. 147-183

[11] STAŇO, J., ŽIŠKA, M.: Solid State Phenomena, 2002, vol. 82-84, pp. 453-458. 